\title{
OR2-002 - The risk of FMF in MEFV heterozygotes
}

\author{
I Jéru ${ }^{1,2,3^{*}}$, V Hentgen ${ }^{4}$, E Cochet ${ }^{3}$, P Duquesnoy ${ }^{1}, G$ Le Borgne ${ }^{1,2}$, E Grimpre ${ }^{2,5}$, K Stankovic Stojanovic $^{6}$, \\ S Karabina ${ }^{1,2}$, G Grateau $^{2,6}$, S Amselem ${ }^{1,2,3}$ \\ From 7th Congress of International Society of Systemic Auto-Inflammatory Diseases (ISSAID) \\ Lausanne, Switerland. 22-26 May 2013
}

\section{Introduction}

Familial Mediterranean fever (FMF) is an autosomal recessive autoinflammatory disorder due to $M E F V$ mutations and one of the most frequent Mediterranean genetic diseases. The observation of many heterozygous patients in whom a second mutated allele was excluded led to propose that heterozygosity could be causal; however, this might often be coincidental due to the very high rate of mutations in Mediterranean populations.

\section{Objectives}

To better delineate the pathogenicity of heterozygosity in order to help genetic counselling and better manage the disease.

\section{Methods}

Complementary statistical approaches were used: estimation of FMF prevalence at population levels, genotype comparison in siblings from 63 familial forms, and genotype study in 557 patients from four Mediterranean populations.

\section{Results}

At population level, we did not observe any contribution of heterozygosity to the disease prevalence. In affected siblings of patients carrying two $M E F V$ mutations, $92 \%$ carry two mutated alleles whereas $4 \%$ are heterozygous with typical FMF diagnosis. We also demonstrated statistically that patients are more prone to be heterozygous than healthy individuals, as shown by the higher ratio heterozygous carriers/non carriers in patients $\left(\mathrm{p}<10^{-7}-\mathrm{p}<0.003\right)$. The risk for heterozygotes to develop FMF was estimated between $2.1 \times 10^{-3}$ and $5.8 \times 10^{-3}$ and the relative risk, as compared to individuals carrying no $M E F V$ mutation, between 6.3 and 8.1 .

\section{Conclusion}

This is the first statistical demonstration that heterozygosity is not responsible for classical Mendelian FMF, but constitutes a susceptibility factor for clinically-similar complex conditions. We also provide a first estimate of the risk for heterozygotes to develop FMF.

\section{Disclosure of interest}

None declared.

\section{Authors' details}

'UMR_S933, INSERM, France. ${ }^{2}$ Université Pierre et Marie Curie-Paris6, France. ${ }^{3}$ Service de Génétique, APHP, Hôpital Trousseau, Paris, France. ${ }^{4}$ Centre de Référence des Maladies Autolnflammatoires, Centre Hospitalier de Versailles, Le Chesnay, France. ${ }^{5}$ Service de Pédiatrie Générale, APHP, Hôpital Trousseau, France. ${ }^{6}$ Service de Médecine Interne, APHP, Hôpital Tenon, Paris, France.

Published: 8 November 2013

doi:10.1186/1546-0096-11-S1-A2

Cite this article as: Jéru et al:: OR2-002 - The risk of FMF in MEFV

heterozygotes. Pediatric Rheumatology 2013 11(Suppl 1):A2. 